\title{
Use of Post-Ionisation Techniques to Complement SIMS Analysis. A Review With Practical Aspects.
}

\author{
H.J. Mathieu and D. Léonard \\ Ecole Polytechnique Fédérale de Lausanne \\ Materials Department, CH-1015 Lausanne, Switzerland. \\ email:mathieu@lmch.dmx.epfl.ch
}

(Received August 12, 1997)

\begin{abstract}
Various ionization techniques for Secondary Neutral Mass Spectrometry (SNMS) (e-beam SNMS, plasma SNMS, laser SNMS in the non resonant and resonant modes) are reviewed as well as their ability to complement Secondary Ion Mass Spectrometry (SIMS). After a brief introduction on the basic principles of SIMS and SNMS, the ionization techniques are compared in terms of their useful yield and ionization efficiency. Several applications from the literature for spectroscopic, imaging and profiling will be given.
\end{abstract}

\section{INTRODUCTION}

Secondary Ion Mass Spectrometry (SMS) /1-21/ is the most sensitive surface analysis technique when compared to X-ray Photoelectron Spectroscopy (XPS) or Auger Electron Spectroscopy (AES) /22/. Reasonable quantification, however, can only be achieved if suitable standards are available and/or the influence of matrix factors (i.e. the unknown ionization probability) can be neglected $/ 12,23,24 /$. This influence represents the severest limitation of the technique for quantitative analysis of both inorganic and organic materials. The unknown surface structure of organic materials and the undefined real sample surfaces represent another limitation. In complement to SIMS analysis, the mass analysis of emitted neutrals in Secondary Neutral Mass
Spectrometry (SNMS) may therefore overcome part of the quantification problem. Analysis of secondary neutrals in SNMS allows a more uniform sensitivity of the detected elements $/ 23,25-31$. This paper intends to describe limitations of SIMS and the way SNMS techniques may help to overcome some of the restrictions. After a brief introduction on the basic mechanisms of SIMS, various SNMS techniques will be reviewed. Examples of spectra, profiles and imaging data illustrate this comparison.

\section{SECONDARY ION MASS SPECTROMETRY}

Under primary bombardment with a focused ion beam, the solid surface emits secondary particles. As illustrated in Fig. 1, the bombardment with primary ions provokes the emission of different, neutral, positively or negatively charged fragments and clusters (and even electrons and electromagnetic radiation). The aim in SIMS is to analyze the sputtered ionized particles as a function of the mass per electric charge, $\mathrm{m} / \mathrm{z}$. Only a small fraction of the emitted fragments is charged either positively or negatively, depending strongly on the particles but estimated to have a mean value of up to 5 $\% / 32 /$. The SIMS process for a given target is described by the following equations

$$
\mathrm{I}_{\mathrm{A}}^{ \pm}=\mathrm{I}_{\mathrm{P}} \mathrm{Y}_{\text {tot }} c_{\mathrm{A}} \gamma_{\mathrm{A}(\mathrm{M})}^{ \pm} \eta_{\mathrm{A}}
$$

and 


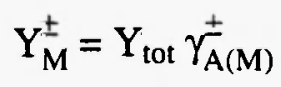

in which $\mathrm{I}_{\mathrm{A}}{ }^{ \pm}$is the detected ion current of species $\mathrm{A}, \mathrm{I}_{\mathrm{p}}$ is the applied primary ion beam current $\left(1 \mathrm{nAcm}^{-2}\right.$ corresponds to approximately $10^{10}$ particles $\mathrm{cm}^{-2} \mathrm{~s}^{-1}$ ), $Y_{\text {tot }}$ the total sputter yield of incident particles, $c_{A}$, the fractional (atomic) concentration of species $A, \gamma_{A(M)}$, the ionization probability for species $A$ in a given matrix $M, \eta_{A}$ the transmission of the analyzer for species $A$ which includes the detector efficiency for species $A$ and $Y_{M}{ }^{ \pm}$, the secondary ion yield of species $A$ (secondary ions/primary ion) depending on the matrix $M$. It is well known that $Y_{M}{ }^{ \pm}$varies over several orders of magnitude as a function of the matrix implying among others that only elements with a low ionization potential or high electron affinity can be detected and imaged with sufficient accuracy to yield high lateral resolution images /14/. For example, $\mathrm{Na}^{+}, \mathrm{Mg}^{+}, \mathrm{Ca}^{+}$, $\mathrm{Ti}^{+}, \mathrm{Fe}^{+}$and $\mathrm{C}^{-}, \mathrm{O}^{-}$and $\mathrm{F}^{-}$(but not $\mathrm{N}^{-}$) ions are characterized by high secondary ion yields. If $\mathrm{A}$ is a molecule, equation (1) must be completed to take into account that recombination reactions could partially be involved. In that case, the concentration of the various parent-like molecules replaces $\mathrm{c}_{\mathrm{A}}$.

The emission of secondary ions involves sputtering and ionization processes. Concerning sputtering, it appears

primary ions

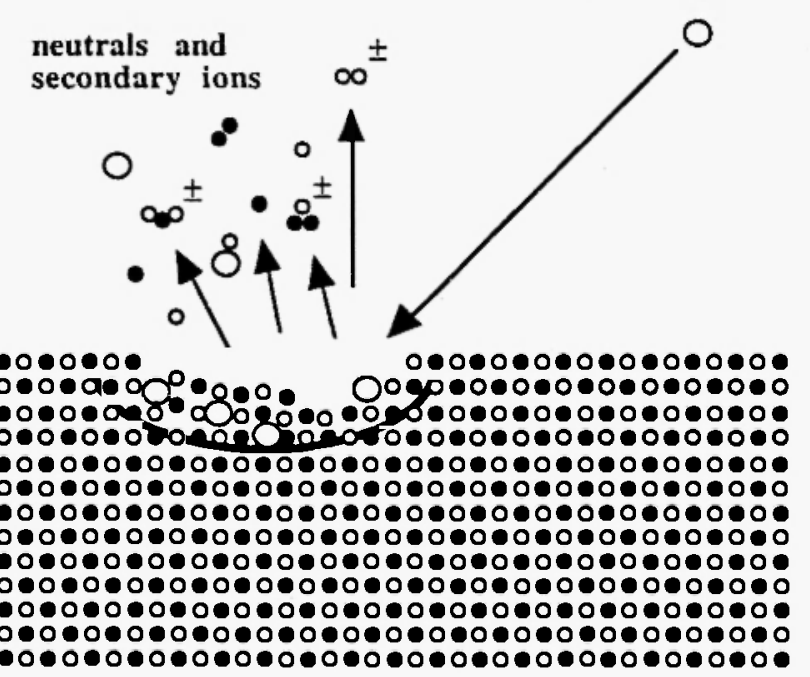

Fig. 1: Schematic diagram of SIMS experiment. Primary ions will produce among others positive, negative and neutral fragments. from calculations simulating the basic ion surface atom collision that for the experimental conditions used in SIMS, the elastic nuclear stopping is the main energy deposition process /33/. However, the influence of electronic stopping should not be neglected /34/. The collision cascade model, developed by Sigmund /35/ is a generalization of the basic collision model. It consists of successive two-body elastic and isotropic collisions between moving and stationary atoms. In spite of the model assumptions, the comparison between experimental data on pure elements (sputtering yields) and simulations based on the collision cascade theory leads to somewhat satisfactory results. However, high mass molecular ions are also detected in SIMS. As discussed by Benninghoven et al. 77 , these high mass fragments can be created by the direct emission of the molecular fragment or through recombination reactions. Another question is the origin: is it the impact site region or outside of this impact site region? Thus, a relevant theory for sputtering needs to consider that all the above processes can be involved and that their relative contribution varies as a function of the material structure. Concerning ionization, there are reviews in the literature of the most relevant ionization models $17,11,13 /$. They can be categorized in the following way: ionization inside the material (bond-breaking model, auto-ionization model, kinetic model); ionization in some excited volume (thermodynamic models) or ionization at some distance from the surface (surface effects models, nascent ion molecule model, 'precursor' model). The idea of recombination reactions is generally not involved except for thermodynamic models. All these ionization processes (rather than one in particular) could be practically involved. In the literature one also finds models characterized by a global description of the sputtering of secondary ions. They involve several ionization and sputtering processes, e.g. direct emission of ionized molecular fragments, selvedge reactions, reactions on the way to the detector, and can explain the very large variation of experimental results. For secondary ion sputtering of organic materials, the main global model are the desorption ionization model /36/ and the Leggett model $/ 37 /$.

The detection of an element as a sputtered ion depends on the primary ion mass, the primary ion energy, the surface structure and the surface chemistry 
$17,11,33 /$. The use of reactive ions such as cesium or oxygen enhances the probability of an ion emission. The presence of oxygen and other electronegative elements in the structure leads to a decrease in the electron neutralization of positive secondary ions, thus enhancing the secondary positive ion yields $138 /$. Finally, the chemistry of the surface can influence the stability of secondary ions (e.g., aromatic ions).

The SIMS sensitivity is also governed by the kind of analyzer used with its limited transmission included in $\eta_{\mathrm{A}}$. RF quadrupole mass filters exhibit a low $\eta_{\mathrm{A}}\left(\sim 10^{-4}\right.$ $\left.-10^{-5}\right)$ combined with low mass resolution $(\Delta \mathrm{m} \approx 1)$. Higher transmission is obtained with magnetic sector double focusing spectrometers $\left(\eta_{\mathrm{AMS})}=10^{-2}-10^{-3}\right.$ ) and Time-of-Flight (ToF) mass analyzers $\eta_{A(T O F)}=1-10^{-1}$ 122,39-41\%. A pulsed ToF-SIMS instrument has parallel detection and the further advantage of a very limited ion fluence needed for secondary ion detection. The achievable mass range, $R$, depends on the analyzer used, i.e. for a quadrupole, $R$ is typically $\angle 500 \mathrm{D}$, whereas for ToF and magnetic sector instruments $R \leq 10^{\prime} 000 \mathrm{D}$ is achieved routinely combined with a mass resolution $\mathrm{m} / \Delta \mathrm{m}>5000$. The lateral resolution and depth resolution depend on the type of primary ion gun used. A liquid metal ion gun like $\mathrm{Ga}^{+}$gives in general a lateral resolution $\leq 0.2 \mu \mathrm{m}$ compared to micrometer resolution for $\mathrm{Cs}^{+}, \mathrm{Ar}^{+}$or $\mathrm{O}_{2}^{+}$. In depth profiling a dynamic range of several orders of magnitude and high sensitivity (low $\mathrm{ppb}$ ) was shown to be achievable by all three types of analyzers $/ 12,14$ /.

The ionic nature of the primary particle must be taken into account in terms of possible charge exchange mechanisms with sputtered neutral species, surface degradation and surface charge accumulation. The low energy electron bombardment is the usual way to perform charge neutralization on poorly conductive surfaces. The surface degradation by the primary ion bombardment implies that primary ion fluences as low as possible should be used. If an already bombarded area is again hit by a primary ion, the surface degradation by the primary ion is observed in the SIMS spectra. This defines the static SIMS analysis conditions: each ion should impact an unaffected area. The generally accepted value of the highest primary ion fluence for SIMS analysis in static conditions are below $10^{13}$ ions $\mathrm{cm}^{-2} / 10,14 /$. However, $10^{12}$ ions $/ \mathrm{cm}^{2}$ seems more reasonable than $10^{13}$ ions $/ \mathrm{cm}^{2}$ because only a tenth of a percent of the top monolayer is bombarded by the primary ion beam. Above such a limit sputter removal takes place in the dynamic regime. Modern instruments can be categorized in "static" and "dynamic" SIMS systems and have imaging capabilities with a lateral resolution determined by the primary ion source. There is always a trade-off between high mass resolution (spectroscopic mode) and high lateral resolution (microscopic mode).

The reader may find various papers on applications of SIMS studies on inorganic and organic material surface characterizations $/ 12,17,19,20,42-45 /$. Only a limited number of articles can be classified as quantitative SIMS studies. They use either standard reference materials (and are thus semi-quantitative studies) or take advantage of the absence of significant matrix effects 77,18 . However, the most important limitation of SIMS microanalysis is caused by intrinsic low ion yield for most of the elements $\left(10^{-1}-10^{-5}\right) / 7,11$, $46 /$, only partially overcome by the use of reactive primary ion sources. Therefore, even if standard reference materials of the unknown sample are available, the difficulty remains to extrapolate to very low concentrations. This is by no means accurate enough in many cases. Another restriction for quantification stems from the fact that $Y_{M}{ }^{ \pm}$can vary by several orders of magnitude as function of surface contamination and matrix composition making quantification rather difficult. The obvious solution to these problems is in principle to detect secondary neutral species.

\section{ELECTRON AND LASER POST- IONIZATION TECHNIQUES}

Demands for quantification and at the same time high sensitivity of organic and inorganic materials characterization have led to the development of several post-ionization techniques: electron beam SNMS, plasma SNMS, SALI (Surface Analysis by Laser Ionization) and SIRIMP (Sputter-Initiated Resonance Ionization Microprobe).

The figure of merit is the "useful yield" $\tau_{A}$. It is defined as the ratio of detected ions to sputtered atoms 
for monoisotopic secondary particles (element or molecular fragments) within the sampling volume. It is equal to the ionization efficiency, $\gamma_{\mathrm{A}}{ }^{0}$, of sputtered neutral species $A$ times the detection efficiency, $\eta_{A}$, which includes the transmission of the instrument $17 /$. The useful yield should be as high as possible to optimize sensitivity within the measuring time while minimizing the materials consumption. Under steady state conditions (or quasi-steady state conditions for the case of depth profiling with large altered layer zones during ion beam mixing), the number of secondary sputtered atoms is proportional to the atomic concentration, $c_{A}$, of that element $A$ due to the conservation of mass. In particular, the observed atomic SNMS signal, $I_{A}{ }^{0}$, can be used for quantification according to $/ 7 /$

$$
I_{A}^{0}=I_{p} Y_{\text {tot }} c_{A} \gamma_{A}^{3} \eta_{A}
$$

The ionization efficiency, $\gamma_{A}{ }^{0}$, is influenced by the choice of applied post-ionisation, whereas the detection efficiency, $\eta_{A}$, as already mentioned, is an instrumental constant for the type of analyzer used. Practically useful yields between $10^{-1}$ and $10^{-9}$ are obtained indicating that the quantification in SNMS is far from simple. $\tau_{\mathrm{A}}$ determines the accuracy of a quantification, which will be improved, if standard reference materials are available. In general, such a reference does not need to be closely matched to the target composition $/ 27 /$. Matrix effects are observable but minimal for all post-ionization techniques except for SIRIMP where the resonant ionization (see below) almost eliminates them 131/.

Post-ionization is achieved by electrons, a plasma, a non-resonant laser or a combination of several lasers for a resonant process. Except further indications, variations in the performance due to the choice of the primary ion source and the ion mass analyzer are similar to those described above for SIMS. However, concentrations with an accuracy $>5 \%$ may be determined with standards by these SNMS techniques.

In electron and plasma SNMS, two fundamentally different approaches are distinguished $/ 27,29,30,47,48 /$. The first approach, e-beam SNMS, is based on the use of a directed flux of essentially monoenergetic electrons towards the sputtered neutrals. As illustrated in Fig. 2

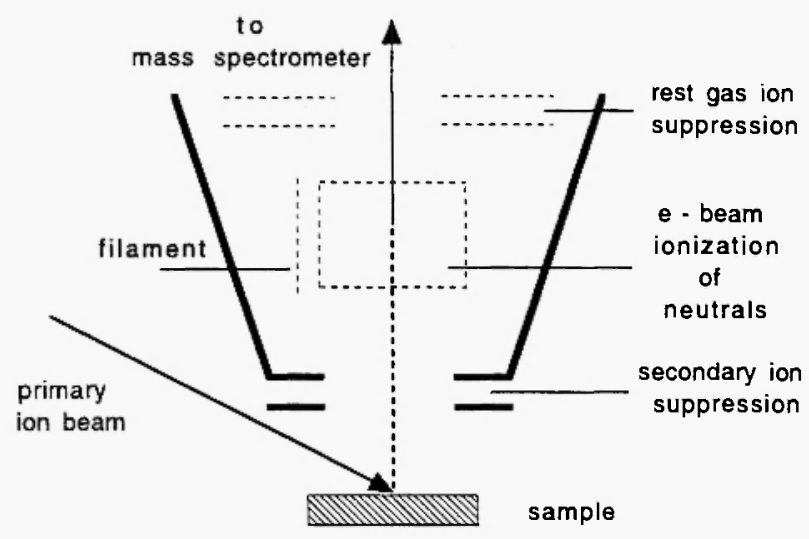

Fig. 2: Electron impact SNMS (schematic).

for e-beam SNMS the target is bombarded at oblique incidence by a focused beam of primary ions. Secondary ions emitted by the target are suppressed. Only the fraction of neutrals entering into the ionization volume is ionized and detected. That fraction of neutrals available for ionization depends on the angular distribution of sputtered particles and is typically around $10^{-4}$ giving a useful yield of $10^{-8}-10^{-9}$ for a quadrupole analyzer $/ 12,27,49,50 /$. A similar, but different approach of e-beam SNMS is proposed by Gersch and Wittmaack 151/. This instrument employs an electron beam directed parallel to the surface ("matched electron beam") allowing higher ionization and collection efficiency (2.5 $\left.x 10^{-3}\right) / 30,51 /$ than the arrangement of Fig. 2. Although the ionization efficiency and the useful yield can be up to a factor 10 - 100 higher, it is more difficult to suppress the secondary ions created at the target for such matched electron beams $/ 30 \%$.

The second approach, e-gas or plasma SNMS, uses a low pressure plasma (usually inert gas, e.g. Ar) /26/ containing ions to sputter the surface and at the same time the e-gas for ionization of the neutrals. The surface is exposed to a plasma induced by an inductively coupled RF circuit. This case is illustrated in Fig. 3 (a). The approach is characterized by the absence of any lateral resolution but by a high depth resolution due to the use of low energetic plasma ions. It couples primary ion bombardment and electron-induced post-ionization and may lead to contamination from the plasma reactor walls. This instrument uses a quadrupole based analyzer with $\eta_{\mathrm{A}} \approx 10^{-5}$. The ionization efficiency is around $10^{-4}$ 126/. Kato et al. $152 /$ proposed a slightly modified 


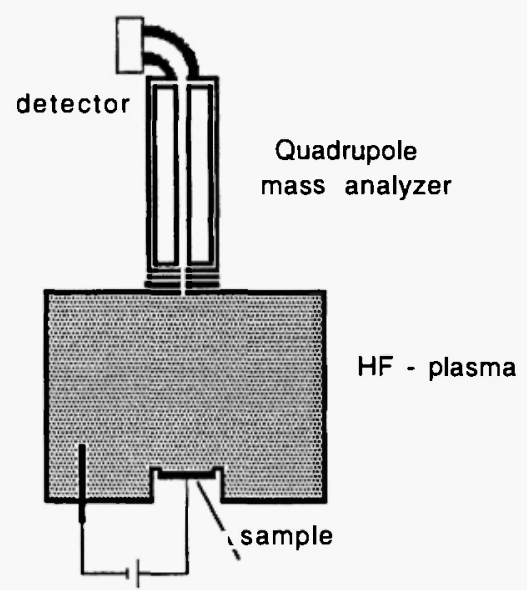

(a)

(b)

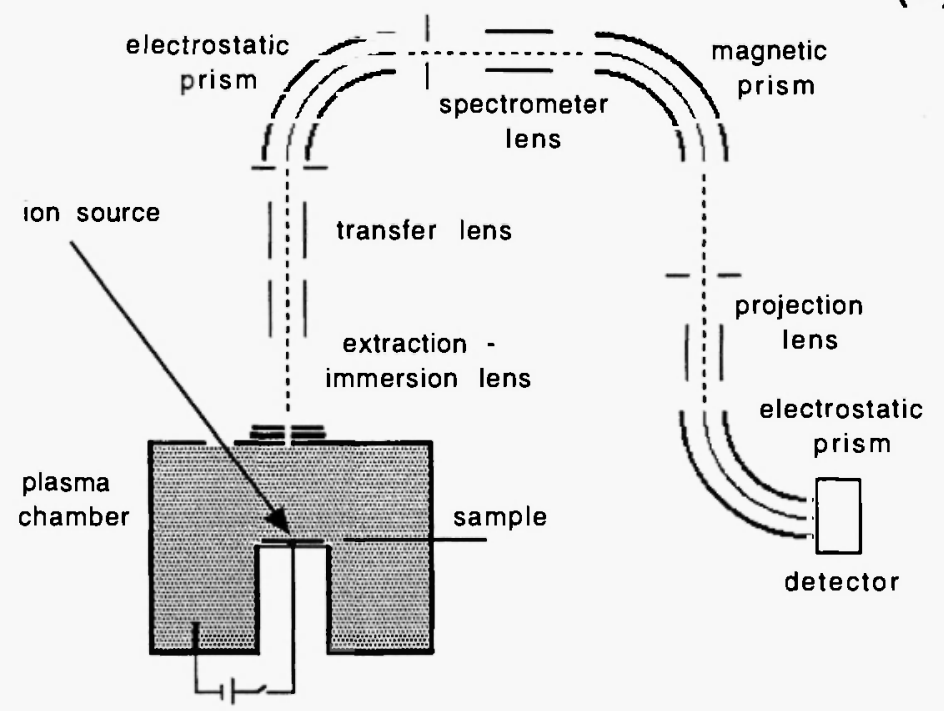

Fig. 3: Principle of plasma SNMS (schematic) (a) HF - plasma is used as sputter source as well as for postionization, (b) microanalyzer with external primary ion source.

plasma SNMS under the acronym SNART (Sputtered Neutral Analysis - Riken Type) using an electron beam excited plasma with low energy ions $(<100 \mathrm{eV})$ at sputter removal rates of a few $\mathrm{nm} / \mathrm{s}$. Some of the inherent disadvantages (no lateral resolution, low mass resolution) were overcome by a recently proposed approach by Bieck and Oechsner /29,53/: microanalysis of solid surfaces is achieved by a focused $\mathrm{Ga}^{+}$beam with plasma SNMS in conjunction with a double focusing magnetic mass spectrometer. It is shown schematically in Fig. 3(b). The ionizing medium consists of the electron component of a low pressure inert gas plasma being resonantly excited inside an ultrahigh vacuum chamber. Ionization efficiencies of a few $10^{-2}$ are achieved. The SNMS useful yield for such an instrument was estimated to be $\approx 10^{-5}$ because of the use of a magnetic sector analyzer. Such an instrument combines the advantages of low primary ion beam energy and direct bombardment $129 \%$. While it is principally designed for laterally resolved SNMS using the external ion beam together with the plasma, it can also be operated in the plasma mode. Although e-beam and plasma SNMS still suffer from a low ionization probability and a relatively low useful yield, it provides a well established quantification scheme $126,27 /$ and Relative Sensitivity Factors (RSF) for many elements 154\%.

The third approach is to achieve post-ionisation by use 
of a laser beam. The laser beam passes parallel to and close to, but above the surface while the surface is probed with a pulsed primary ion beam together with a TOF analyzer. Two ways for laser-induced post-ionization are applied, which can saturate transitions from the ground or excited states of sputtered neutrals. The first method is the nonresonant approach applying single photon ionization (SPI) or multiphoton ionization (MPI) known under the acronym SALI ${ }^{\circ}$ 155-57/. The second method, the resonant approach, is known as Multi Photon Resonance Ionization (MPRI), Sputter-initiated Resonance Ionization Spectroscopy (SIRIS) or Sputter-initiated Resonance Ionization Microprobe (SIRIMP). After removal of the secondary ions the secondary neutrals are resonantly ionized before being detected by a TOF analyzer $/ 31,58-66 /$.

SALI ${ }^{\otimes}$ uses the constant radiation of a standard pulsed excimer laser (usually $\mathrm{KrF}$ at $248 \mathrm{~nm}-5 \mathrm{eV}$ - or ArF at $193 \mathrm{~nm}-6.4 \mathrm{eV}-$ ) or a VUV laser (118 nm -10.5 $\mathrm{eV}-$ ) focused above the surface to produce $10^{+10} \mathrm{~W} / \mathrm{cm}^{2}$ or $10^{+7} \mathrm{~W} / \mathrm{cm}^{2}$, respectively. Such a power laser is generally sufficient to saturate the ionization for a nonresonant two photon process. A single or multi-photon transition is obtained through virtual states as illustrated in Fig. 4 for the case of a single or two-photon process. The single photon ionization is virtually a non-resonant process, because no particular wavelength is needed $/ 67 /$. The ionization potentials, $\Phi$, are element specific as shown in Fig. $5 / 46 /$. Inspection reveals that for most elements, more than $5 \mathrm{eV}$ energy is needed for ionization, and even with a radiation of ArF $(6.4 \mathrm{eV})$, a two-photon process is not sufficient for ionization of hydrogen, nitrogen, oxygen, fluorine, chlorine and noble elements ( $\mathrm{He}, \mathrm{Ne}, \mathrm{Ar}, \mathrm{Kr}$ ) $/ 68 /$. Photo-ionization and -fragmentation of the sputtered particles may take place within the laser illuminated volume adjacent to the sample surface, thus complicating quantification $/ 69 /$.

A typical SALI ${ }^{\circledR}$ experimental setup is illustrated in Fig. 6 for a combined SIMS/laser-SNMS instrument

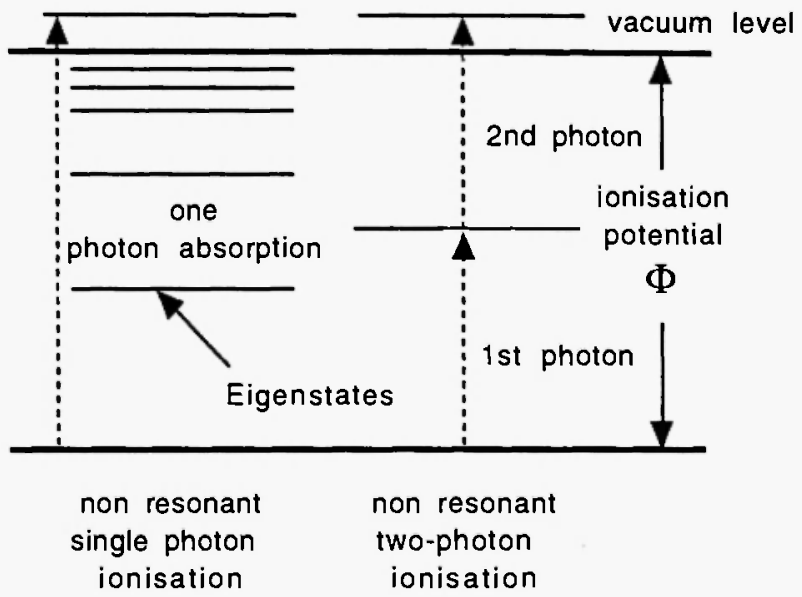

Fig. 4: Principle of non resonant post-ionization for single photon and two-photon ionization

\section{$\Phi[\mathrm{eV}]$}

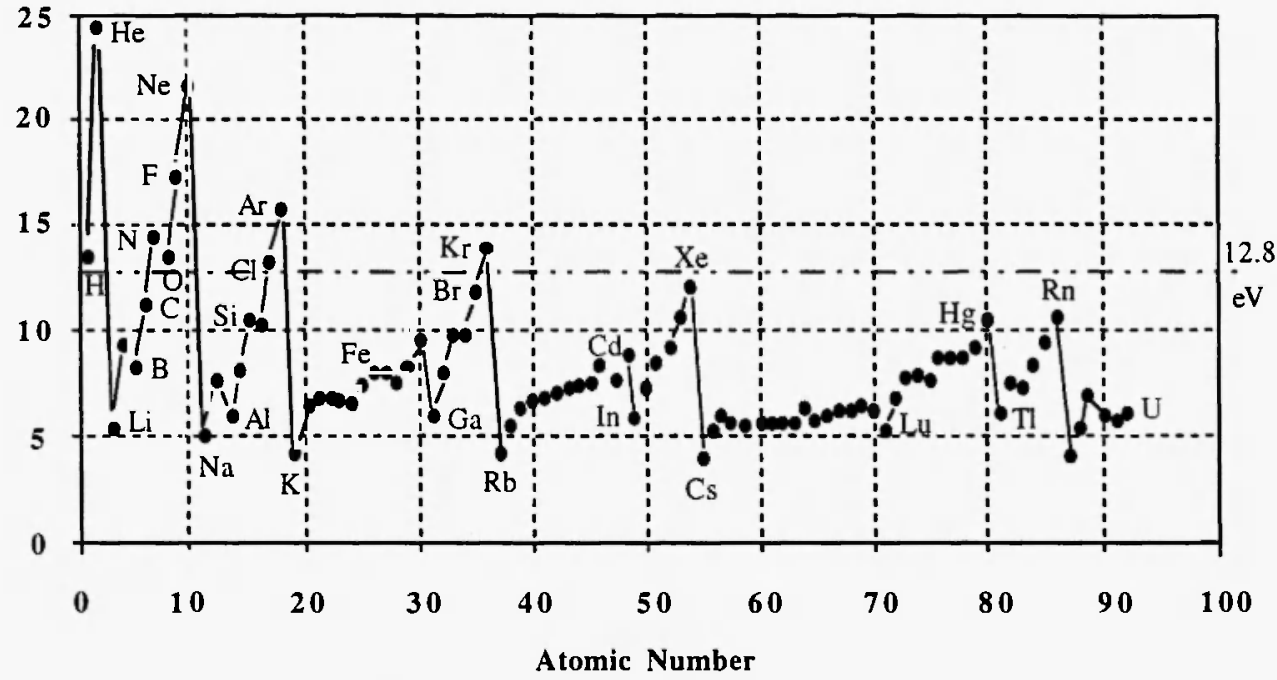

Fig. 5: First ionization potentials after $/ 68 /$. 


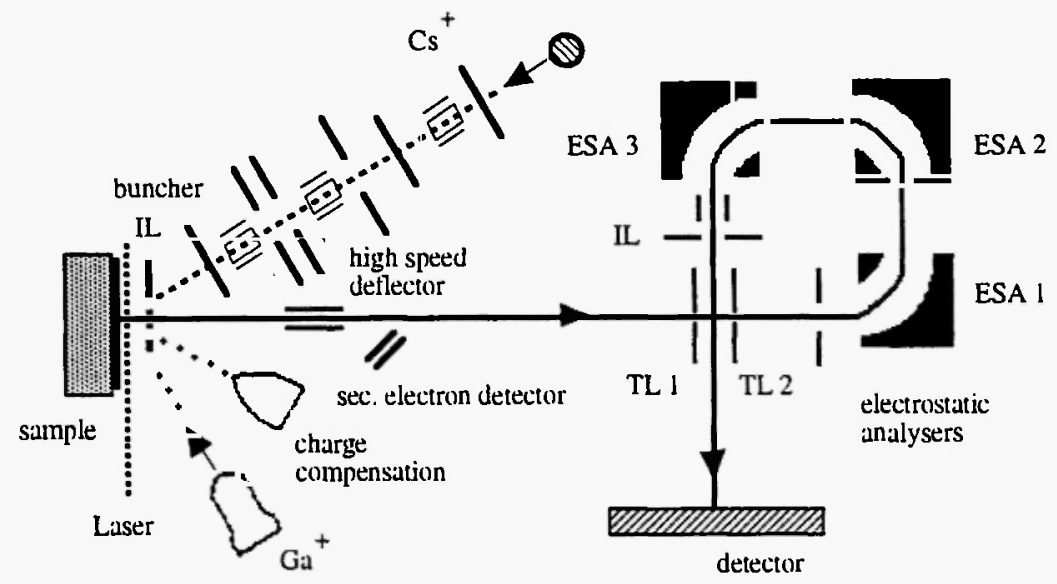

Fig. 6: Schematic diagram of a Trift ToF-SIMS/ SNMS mass spectrometer - ESA 1 - 3 are electrostatic analyzers, IL is an immersion lens, TL1 and TL2 are transfer lenses after $/ 24 \%$.

equipped with two ion sources $\left(\mathrm{Cs}^{+}\right.$and $\left.\mathrm{Ga}^{+}\right)$and a Time-of-Flight Trift analyzer /41/. The laser source is a pulsed excimer laser operated with $\mathrm{KrF}$ at $248 \mathrm{~nm}$. The laser beam post-ionizes the neutrals within less than one $\mathrm{mm}$ in front of the surface. The volume in which the ionization takes place is above the surface. This may reduce therefore the lateral resolution depending on the focus conditions of the ion beam. It should be noted that TOF-SIMS and laser SNMS use different ion detection systems. In the former case, a time-to-digital converter (i.e. an ion counter) is employed, whereas in the latter case, a transient recorder (i.e. a current amplifier) is used due to the low repetition rate $(10-400 \mathrm{~Hz})$ of currently available lasers. In the case of pulsed laser ionization the intrinsic mass resolution for laser-SNMS is related to the laser pulse width ( $8 \mathrm{~ns}$ in this case) which is larger than the pulse width of the bunched ion beam used for SIMS analysis (1 ns). Moreover, during the laser-SNMS analysis the primary ion beam pulse width must be increased to high values $(1 \mu \mathrm{s})$ in the laser-SNMS mode to avoid any mass discrimination artifacts. Such a laser-SNMS combined with a TOF analyzer has a typical useful yield of $\tau_{\mathrm{A}} \approx 10^{-4} / 27 /$. A similar experimental setup equipped with a reflectron type analyzer, but with a femtosecond laser pulse is reported by Terhorst $e t$ al. with improved useful yields up to $10^{-2} / 28,70,71 /$.

The Sputter-initiated Resonance Ionization Resonance Microprobe (SIRIMP) combines the resolution and sputter capabilities. Its principle is illustrated in Fig. 7 indicating that one or more additional photons may be needed for a final transition to the autoionizing level as discussed by Arlinghaus 131/. The very high sensitivity for SIRMP is explained by the extremely high ionization cross sections (several orders of magnitude) compared to the non-resonant case. In combination with a ToF analyzer useful yields of $10^{-1}-1$ are obtained. As for SALI ${ }^{\otimes}$ unity ionization efficiency is reached for more than $80 \%$ of the elements 131\%. Because the process is element selective, it produces fewer isobaric and molecular interferences than SALI ${ }^{\otimes}$. Therefore, the mass and energy selectivity of resonant ionization almost eliminates the need for mass spectrometry. It remains its main drawback that only one element is analyzed at a time

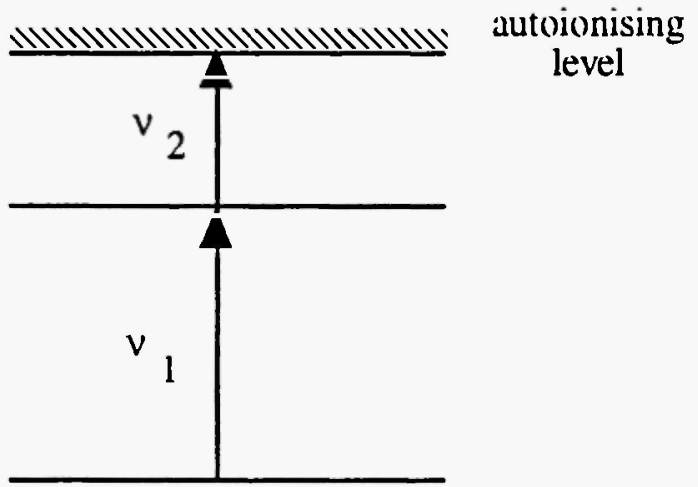

Fig 7: Principle of a resonant two-photon postionization (SIRIMP), after /31/. The first step (v1) may be obtained with a tunable dye laser and the second step ( $v 2)$ with an Excimer laser. 
and that currently a low repetition rate of pulsed lasers impose a low duty cycle $(\approx 400 \mathrm{~Hz}$ ). Advances in diode-pumped Nd:YAG lasers and optical parametric oscillators (OPO's) will allow to increase the repetition rate from currently $100-400 \mathrm{~Hz}$ to $600 \mathrm{~Hz}$ or higher /31/.

\section{APPLICATIONS}

The following examples of SIMS and post-ionized SNMS should illustrate the difference of information that can be obtained for spectra, images and profiles using all these techniques.

Fig. 8 shows (a) positive SIMS (b) e-beam SNMS spectra of $\mathrm{GaAs}$ measured with a $3 \mathrm{keV} \mathrm{Ar}^{+}$primary ion beam at a current of $\mathrm{Ip}=1 \mu \mathrm{A}$ at $55^{\circ}$ incidence using an electron impact ionizer and a quadrupole mass analyzer $/ 50 /$. Changing from SIMS to SNMS was possible within milliseconds by switching electrostatic potentials only. The bombardment conditions for both spectra were the same and the difference in intensity between them can be directly attributed to the difference in ionization probability between $\mathrm{Ga}$ and As. During postionization (b) of neutrals, both signals, $\mathrm{Ga}$ and As, are approximately of equal intensity corresponding to the original stoichiometry of $\mathrm{GaAs}$. However, the $\mathrm{Ga}$ intensity ratio of singly charged postionized atoms to secondary ions is only $1 / 20$, i.e. the sensitivity in SIMS analysis of elements like $\mathrm{Ga}$ is significantly higher than in SNMS. The background and impurities signals (like
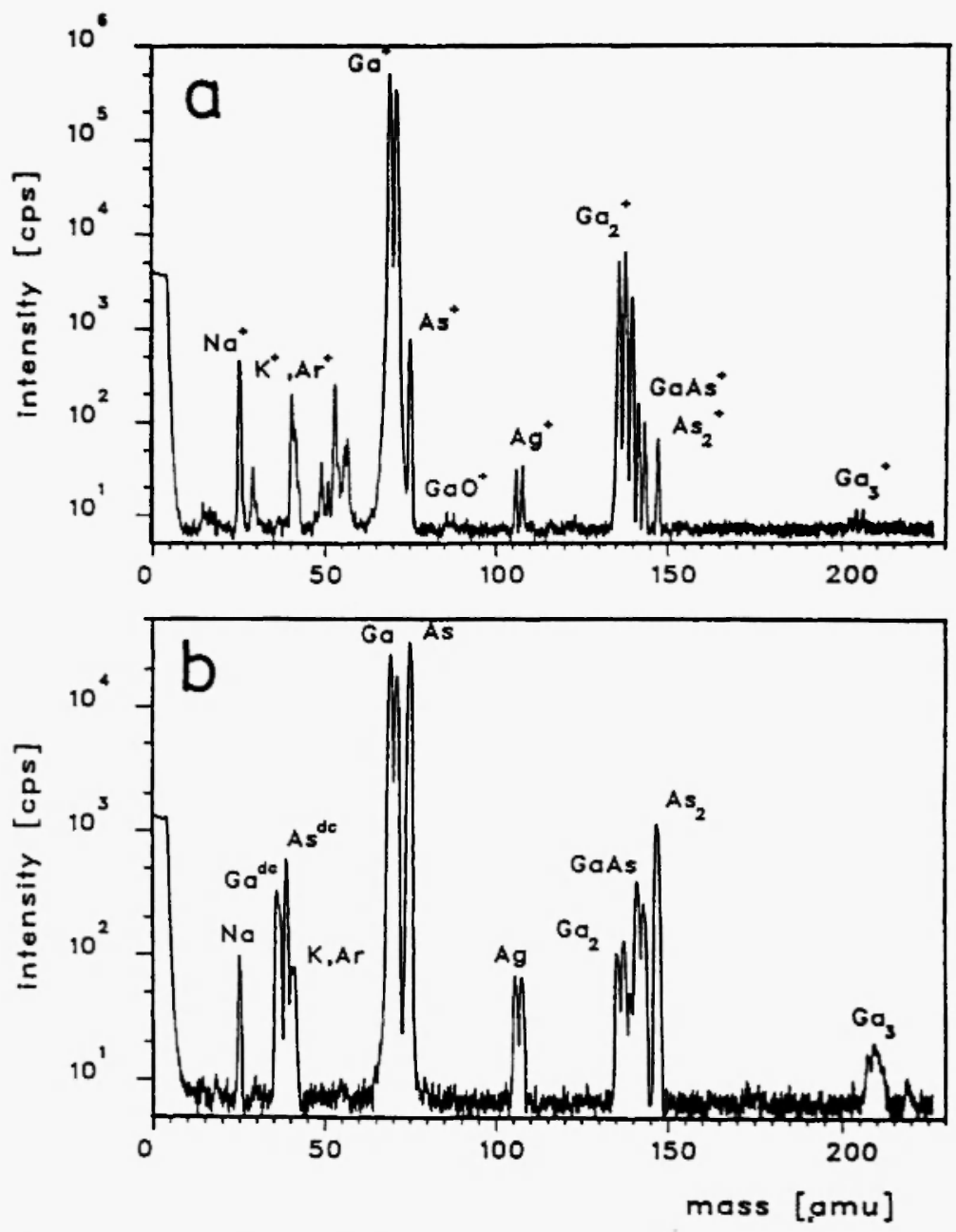

Fig 8: (a) Positive SIMS spectrum of GaAs ( $3 \mathrm{keV} \mathrm{Ar}^{+}, \mathrm{I}_{\mathrm{p}}=1 \mu \mathrm{A}$, scan speed $1 \mathrm{amu} / \mathrm{s}$ ). (b) SNMS spectrum of $\mathrm{GaAs}$ ( $3 \mathrm{keV} \mathrm{Ar}{ }^{+}, I_{p}=1 \mu \mathrm{A}, \bar{I}_{\mathrm{em}}=1.3 \mathrm{~mA}$, scan speed $0.2 \mathrm{amu} / \mathrm{s}$ ). The silver signals in both spectra originate from the sample holder - with permission by the authors $/ 50 \%$. 
$\mathrm{Na}$ are similar. The low mass resolution is due to the fact that, for those early measurements, a quadrupole mass analyzer was used. This example demonstrates that the simple and easy e-beam ionization of neutrals allows to eliminate the influence of the matrix effect in GaAs effectively for single ionized neutrals. The influence of the e-beam geometry is discussed by Gersch and Wittmaack /51/ who use among other examples also GaAs as a model sample. They demonstrate an improved useful yield due to the matched electron beam, which arrives parallel to the surface. Using a ToF reflectron type mass analyzer in combination with an e-beam post-ionization, better mass resolution $(\mathrm{m} / \Delta \mathrm{m}>3500)$ has been reported for $\mathrm{Si}$ wafer applications $171 \%$ Other examples on the efficiency in eliminating the influence of matrix effects in mass spectra thanks to neutral post-ionization, but mostly with laser non-resonant multi-photon postionization of neutrals, are found elsewhere $/ 27,72 /$. Relative Sensitivity Factors (RSF) have been determined for metals on $\mathrm{Si}$ wafers for $\mathrm{ArF}$ and $\mathrm{KrF}$ excimer laser-SNMS /73/, as well as for metal alloys and oxides with detection limits lying between $10^{8}$ and $10^{10}$ atoms $/ \mathrm{cm}^{2} / 71,74 /$.

Figs. 9 and 10 illustrate the imaging capabilities of SIMS and SNMS, respectively. SIMS data were acquired with the Trift ToF-SIMS system shown in fig. 6 (using a pulsed $25 \mathrm{keV} \mathrm{Ga}{ }^{+}$source) on a ternary $\mathrm{FeCrNb}$ alloy which exhibited a dendritic structure $/ 75 /$. One observes a complementary composition for $\mathrm{Cr}$ and $\mathrm{Nb}$. A line scan across the $\mathrm{Nb}$ image indicates that micron lateral resolution is easily achieved. Fig. 10 illustrates SNMS imaging results by Berthold and Wucher /76/ taken also with a pulsed $25 \mathrm{keV} \mathrm{Ga}^{+}$source on model samples of nickel grids of $20 \mu \mathrm{m}$ width pressed into polycrystalline silver foil. It shows images and line scans from $\mathrm{KrF}$ pulsed Excimer laser (Lambda LPX120i) SNMS with a pulse duration of $20 \mathrm{ns,} \mathrm{energy}$ of $300 \mathrm{~mJ}$ at $248 \mathrm{~nm}$ wavelength. Post-ionization at a peak power density of $10^{9} \mathrm{~W} / \mathrm{cm}^{2}$ was sufficient to nearly saturate the non-resonant two-photon ionization of ${ }^{107} \mathrm{Ag},{ }^{58} \mathrm{Ni}$ and ${ }^{64} \mathrm{Ni}$ isotopes. The laser beam was located at a distance of approximately $1 \mathrm{~mm}$ above the surface and directed parallel to the surface. The
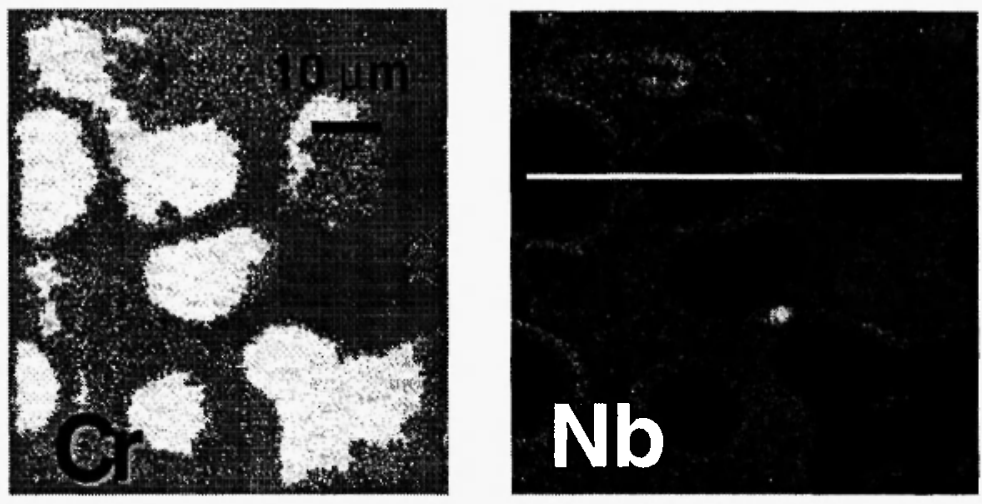

\section{FeCrNb alloy}

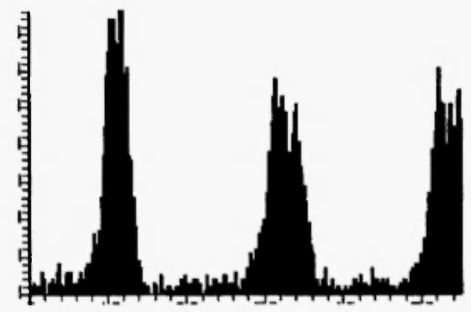

Fig. 9: ToF-SIMS image of $\mathrm{Cr}^{+}$and $\mathrm{Nb}^{+}$distribution on passive film of $\mathrm{Fe}-25 \mathrm{Cr}-1 \mathrm{lNb}$ alloy and corresponding line scan for $\mathrm{Nb} / 75 /$. 

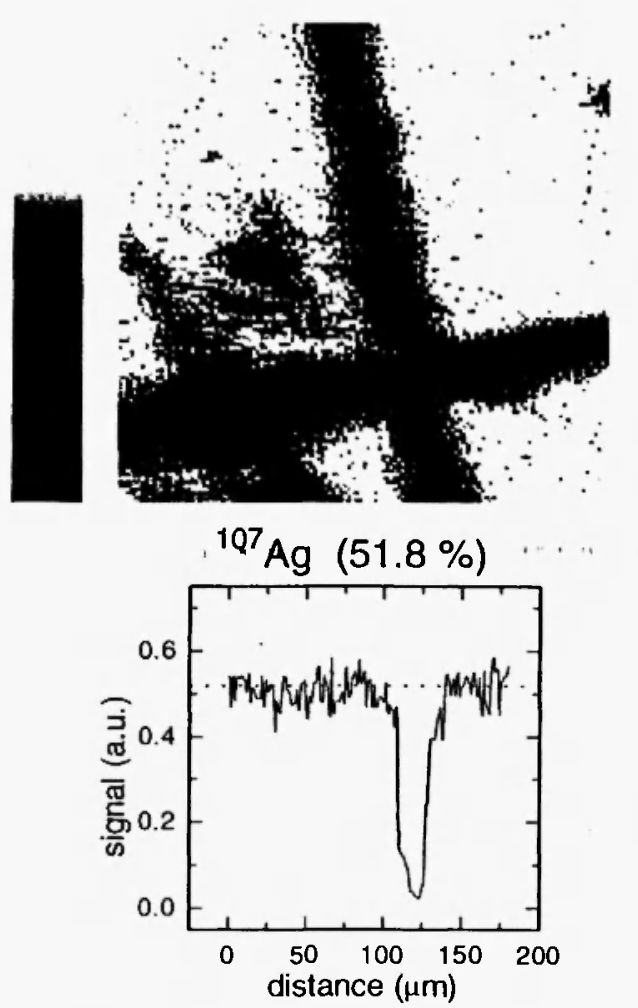
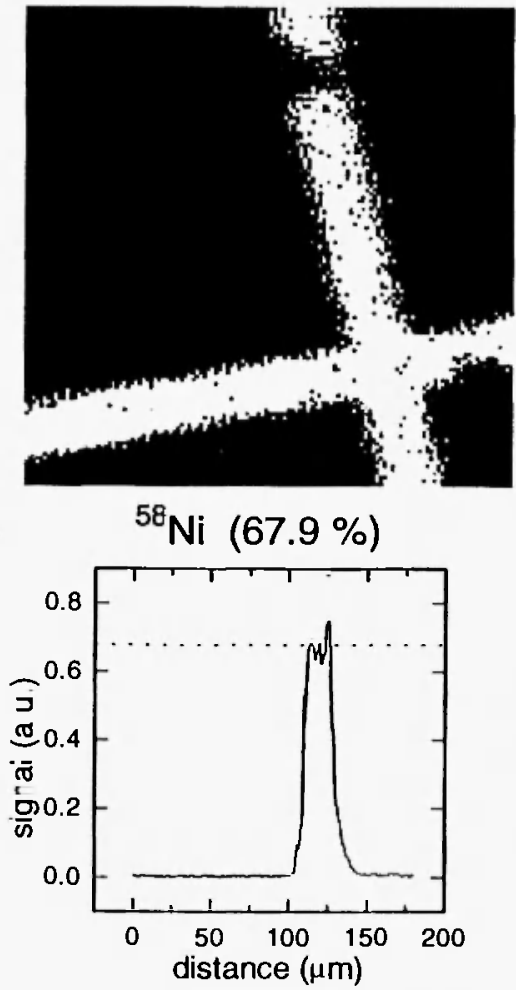
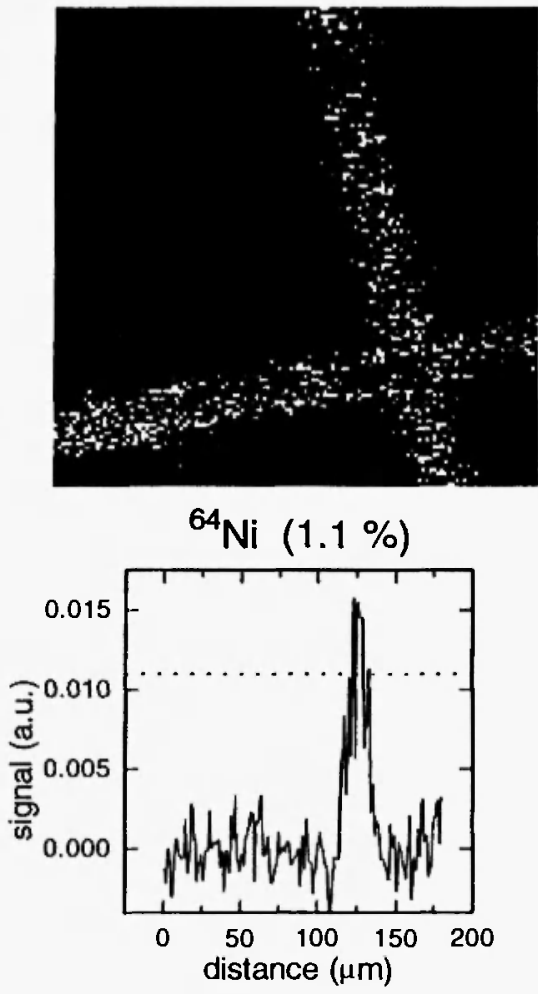

Fig. 10: $\mathrm{Ag}$ and Ni laser SNMS reflectron ToF-SIMS images and line scans of a Ni grid (300 $\mu \mathrm{m}$ mesh width, $20 \mu \mathrm{m}$ bar width) pressed into a silver substrate. Field of view $175 \mu \mathrm{m}$ x $175 \mu \mathrm{m}:{ }^{107} \mathrm{Ag}$ signal, ${ }^{58} \mathrm{Ni}$ signal and ${ }^{64} \mathrm{Ni}$ signal, with permission by the authors $/ 76 /$.

photo-ions created were extracted towards a reflectron ToF mass spectrometer using a $400 \mathrm{MHz}$ transient recorder for parallel detection. Fig. 10 clearly indicates that the ${ }^{64} \mathrm{Ni}$ isotope at $\mathbf{1 . 1}$ at\% abundance is detectable with a signal/noise ratio of five for the line scan. This means a detection limit of 0.2 at $\%$ with a signal/noise ration of 1 for a beam diameter of $1 \mu \mathrm{m}$ at $6 \mathrm{nA}$ beam current. Extrapolation of these results gives a detection limit of $\approx 100 \mathrm{ppm}$ for a beam diameter of $10 \mu \mathrm{m}$ at $\mathbf{5 0}$ nA beam current in agreement with Mouncey et al./77/. Fig. 10 together with the cited literature data demonstrate that for the same primary ion source there is practically no loss of lateral resolution when compared to SIMS. Recently, ultra short pulsed laser postionization for the detection of neutral atoms and molecules desorbed from surfaces has been applied 178-81/. It was demonstrated that such ultra short pulses ( $<500 \mathrm{fs})$ are useful in molecular imaging. The control of molecular fragmentation in post-ionization experiments was investigated by Willey et al. /82/ using
$150 \mathrm{fs}$ at $800 \mathrm{~nm}$ with $1.6 \mathrm{~mJ}$ pulse energy. This femtosecond laser source uses a Ti:sapphire oscillator pumped with $3.3 \mathrm{~W}$ from $\mathrm{Ar}^{+}$generating a pulse width of $\sim 250 \mathrm{fs}$ at a repetition rate of $1 \mathrm{kHz}$. They show that such a high repetition rate of laser greatly increases the possibilities for molecular imaging.

Examples of ToF-SIMS as well as laser-SNMS sputter depth profiles of $30 \mathrm{~nm} \mathrm{Ta} \mathrm{O}_{5} / \mathrm{Ta}$ BCR standard samples [*] are shown in Figs. 11 and 12, respectively 124/. Data were taken with the experimental system shown in Fig. 6. Sputter depth calibration was achieved by converting the sputter time necessary to reach the oxide - metal interface at $30 \mathrm{~nm}$ into depth assuming a constant sputter speed. The profiles were achieved by means of a sequence of two alternating cycles: at first, the ToF data acquisition was performed using a pulsed ${ }^{133} \mathrm{Cs}^{+}$beam with a pulse width of $\leq 1 \mathrm{~ns}$ for the bunched primary beam at a repetition rate of $\sim 15 \mathrm{kHz}$ in the SIMS mode $(\sim 1 \mu s$ and $76 \mathrm{~Hz}$, respectively in the laser-SNMS mode), followed by a dc sputter cycle 


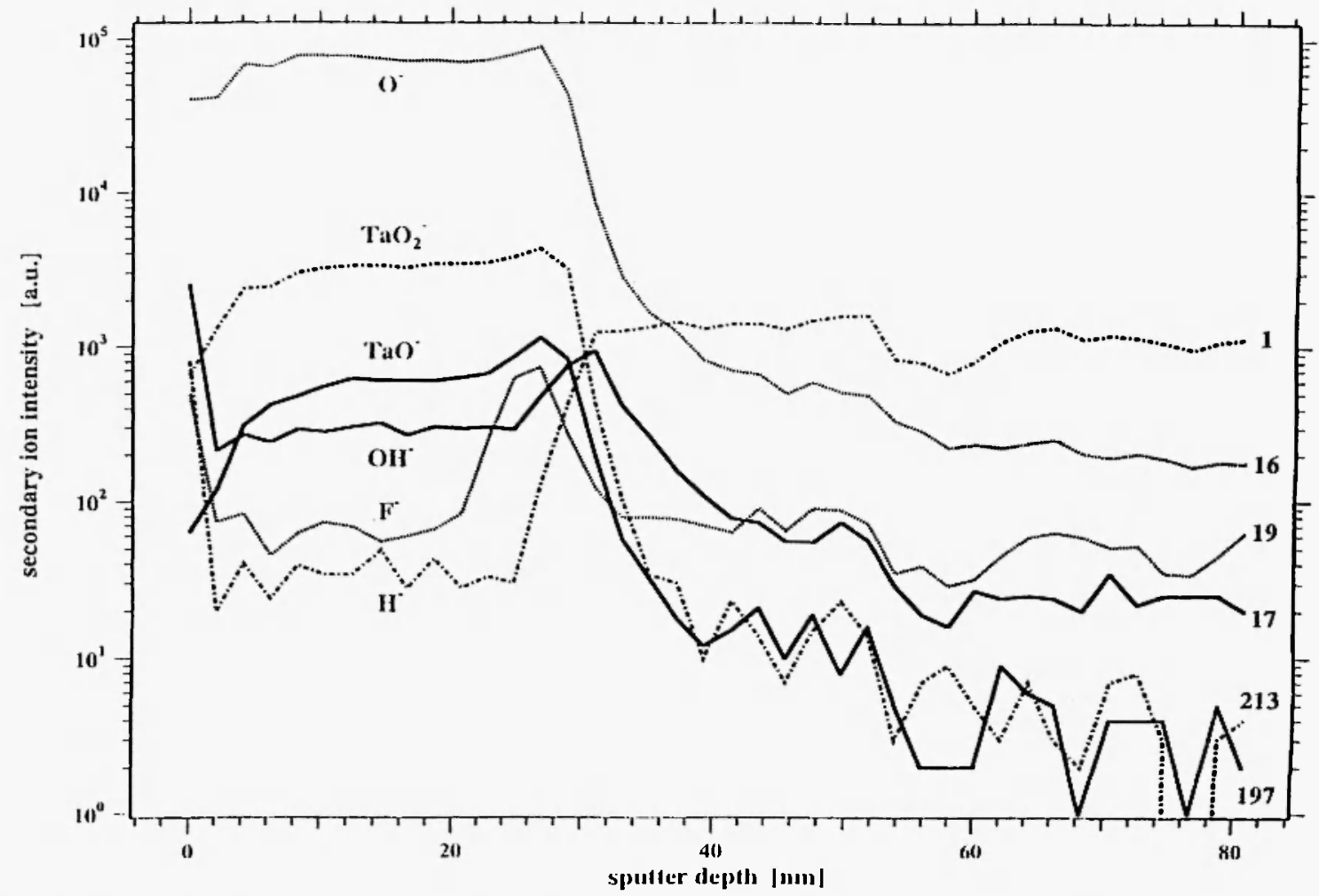

Fig. 11: Negative SIMS sputter depth profile of standard $30 \mathrm{~nm} \mathrm{Ta}_{2} \mathrm{O}_{5} / \mathrm{Ta}$ using $14 \mathrm{keV} \mathrm{Cs}{ }^{+}$ion bombardment $/ 24 /$.

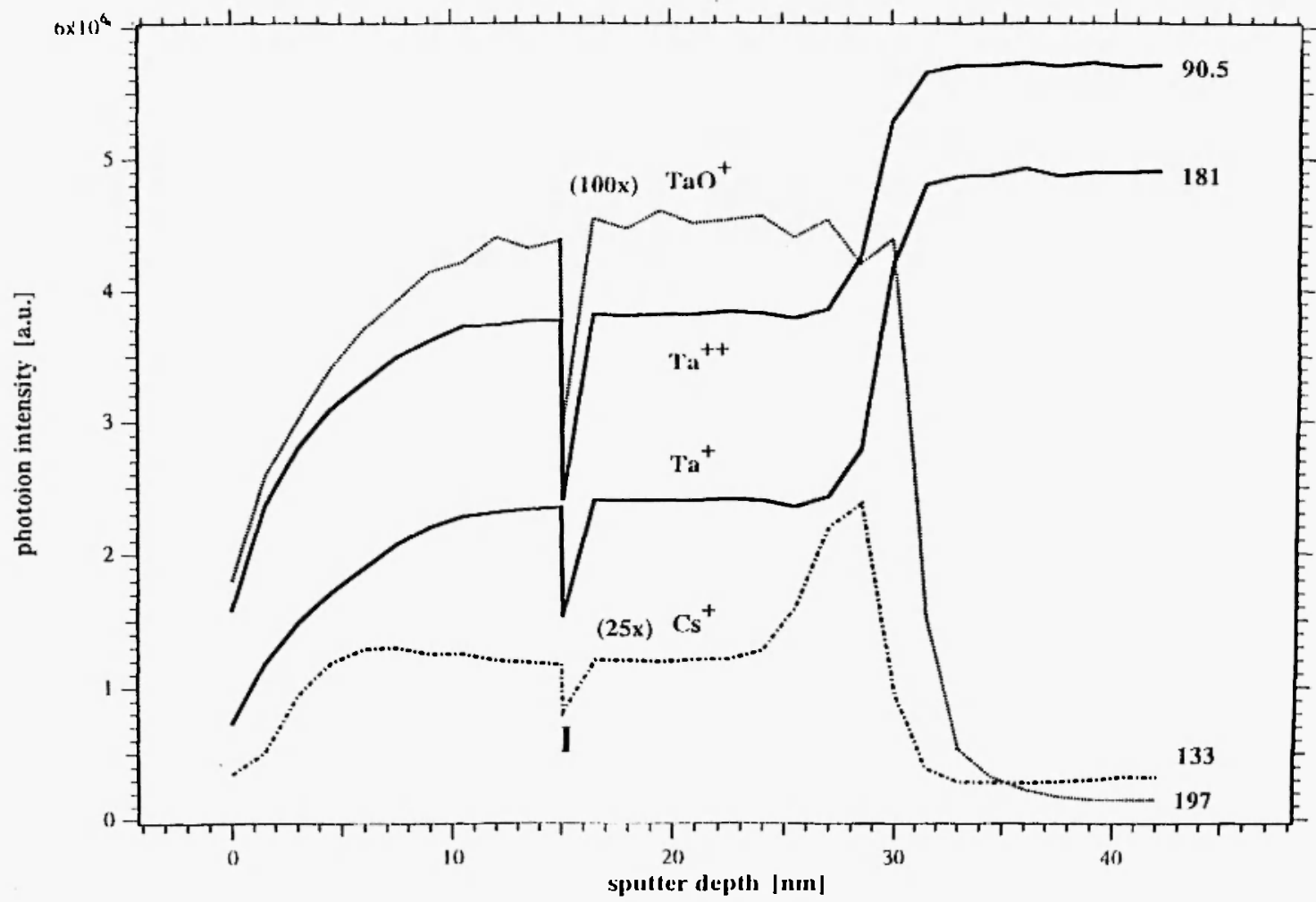

Fig. 12: Positive laser-SNMS sputter depth profile of standard $30 \mathrm{~nm} \mathrm{Ta} \mathrm{O}_{5} / \mathrm{Ta}$ using $7.6 \mathrm{keV} \mathrm{Cs}{ }^{+}$ion bombardment. The vertical bar at $\sim 15 \mathrm{~nm}$ indicates that profiling was interrupted for a waiting period of $\sim 5 \mathrm{~min} / 24 /$. 
during which the primary ion beam continuously bombarded a larger area. Sputter times per cycle were chosen to be 10,15 or $30 \mathrm{~s}$, whereas data acquisition times per cycle were 30 or $60 \mathrm{~s}$. The size of the sample surface used for data acquisition was typically $\sim 200 \times 200 \mu \mathrm{m}$ while the size of the square sputter crater was $-620 \times 620 \mu \mathrm{m}$. Post-ionization was achieved by a KrF pulsed Excimer laser (Lambda LPX 140i) with a pulse duration of $8 \mathrm{~ns}$ and an intensity of approximately $10^{10} \mathrm{~W} / \mathrm{cm}^{2}$ at a focus size of $100 \mu \mathrm{m}$ at $0.5 \mathrm{~mm}$ above the sample surface. Fig. 11 shows the negative SIMS profile obtained with $14 \mathrm{keV}{ }^{133} \mathrm{Cs}^{+}$. The most intense secondary ion signals are displayed. Less intense peaks monitored but not shown here are described elsewhere 124/. Intensities of 'oxide-type' ion species (i.e. $\mathrm{O}$; $\mathrm{TaO}_{2}^{-}, \mathrm{TaO}$ ) decrease sharply at oxide/metal interface. $\mathrm{F}$ is present at the interface as a contamination because HF etching was applied before anodizing Ta. $\mathrm{H}$ increases drastically and remains constant at the reactive $\mathrm{Ta}$ - surface due to readsorption and also due to hydrogen diffusion within $\mathrm{Ta}$. Intensities of 'hydroxide-type' ion species like $\mathrm{OH}^{-}$show a pronounced maximum at the interface. The low dynamic range $\left(<10^{3}\right)$ is very likely due not only to the nature of the anodic preparation of the films, but also due to the laser beam creating a higher background level of the signal. Quantification SIMS data (not shown) gave a four-fold increase for the surface concentration $c_{2}\left(\mathrm{CsTa}^{+}\right)$from the oxide $\left(\mathrm{Ta}_{2} \mathrm{O}_{5}\right)$ to the metal (Ta) compared to the expected increase of a factor of two 124/. Depth resolution at the oxide/metal interface was found to be $\sim 1 \mathrm{~nm}$. Fig. 12 displays a positive laserSNMS sputter depth profile obtained with $7.6 \mathrm{keV}$ ${ }^{133} \mathrm{Cs}^{+}$. The vertical bars shown in Fig. 12 at a sputter depth of $\sim 15 \mathrm{~nm}$ indicate that the data acquisition was interrupted for a period of $5 \mathrm{~min}$. This illustrates how much the measured ion signals can be affected by surface re-poisoning of the sputter-cleaned reactive crater bottom. Quantification is still not straightforward, due to possible photo-fragmentation of sputtered neutrals, i.e it is not clear if the post-ionized signal is due to a two-photon post-ionization or due to the ionization of a photo fragment originating from more complex molecular parents $124,26,69,83 /$. In this case, the difference in intensity between $\mathrm{I}\left(\mathrm{TaO}^{+}\right)$and $\mathrm{I}\left(\mathrm{Ta}^{+}\right)$ may be attributed to predominant photo-fragmentation of sputtered $\mathrm{TaO}$, leading to an enhanced $\mathrm{Ta}^{+}$photo-ion signal or to a drastic reduction of the formation of sputtered $\mathrm{TaO}$ due to reactive ion implantation. The most important result from the post-ionized data (Fig. 12) is the increase of the photo-ion signal of $\mathrm{Ta}^{+}$by a factor of $\sim 2$ at the oxide/metal interface. Assuming the total sputter yield $Y_{\text {tot }}$ to decrease at the interface by a factor of 1.8 as found by Schoof $/ 84 /$, an increase of the Ta bulk concentration by a factor of $\sim 3.6$ is expected comparing nicely with the bulk atomic concentration rise of $\mathrm{Ta}, \mathrm{c}_{b}, \mathrm{Ta}$, from $2 / 7$ expected for $\mathrm{Ta}_{2} \mathrm{O}_{5}$ to 1 in the metal, indicating that quantification of laser SNMS was clearly more accurate than of SIMS. As shown in Fig. 12 sputter depth resolution of $\sim 1 \mathrm{~nm}$ was achieved using laser SNMS.

The last example concerns SIRIMP measurements by Arlinghaus et al. 166/. A sputter depth profile of $\mathrm{Cu}$ implanted in silicon with $50 \mathrm{keV}, 1 \times 10^{14}$ atoms $/ \mathrm{cm}^{2}$ was measured with a pulsed $10 \mathrm{keV} 1 \mu \mathrm{A} \mathrm{O}_{2}{ }^{+}$beam raster scanned over $0.4 \times 0.8 \mathrm{~mm}$. Fig. 13. shows typical depth profiles of ${ }^{63} \mathrm{Cu}$ and ${ }^{65} \mathrm{Cu}$ using a ToF mass analyzer. No

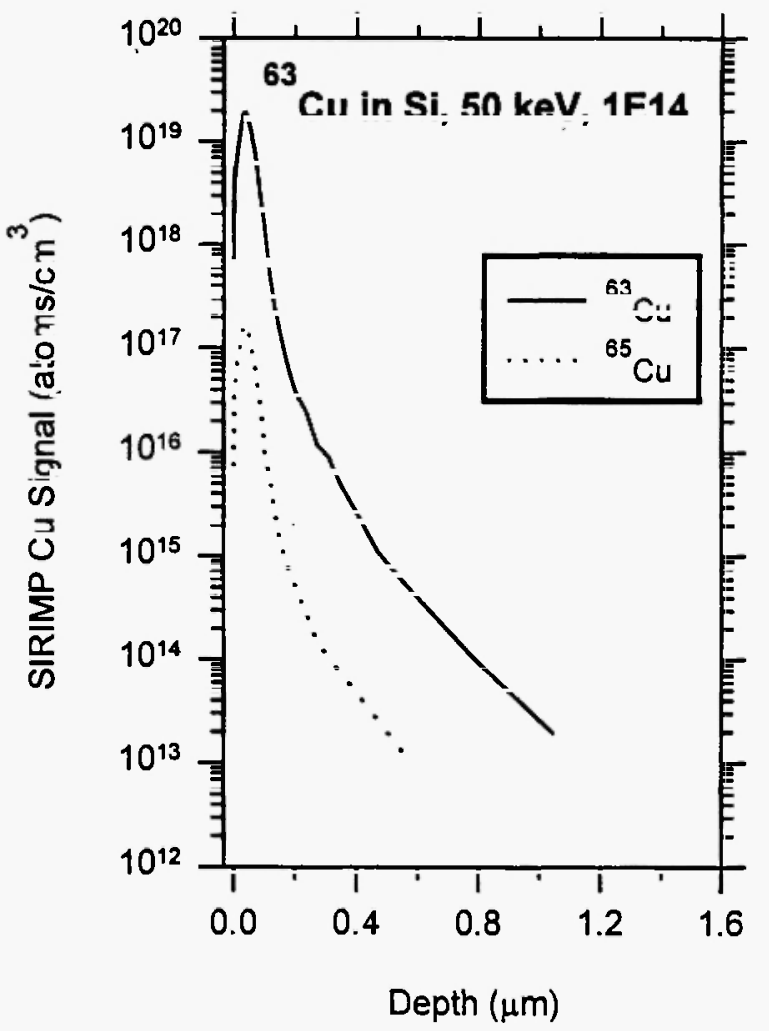

Fig. 13: SIRIMP depth profiles of ${ }^{63} \mathrm{Cu}$ and ${ }^{65} \mathrm{Cu}$ isotopes in silicon, with permission by the authors /66/. 
significant differences were observed for the dynamic range when using an $\mathrm{Ar}^{+}$beam. As outlined above, using SIRIMP, only one element (isotope) is profiled during post-ionization in the resonant mode. Both the experimentally determined peak concentrations and the depth position of the peaks are in good agreement with those calculated using the TRIM89 code, demonstrating the high instrumental accuracy possible with SIRIMP. The dynamic range of ${ }^{63} \mathrm{Cu}$ is better than six orders of magnitude. The trailing edge of the profile is at a concentration of approximately $2 \times 10^{13}$ atoms $/ \mathrm{cm}^{3}(400$ $\mathrm{ppt)}$. The same authors applied also SIRIMP to measure $\mathrm{Cu}$ contamination in CdZnTe (CZT) films. Figure 14 shows SIRIMP 3D images of copper concentration around $\mathrm{Te}$ and $\mathrm{Cd}$ inclusions /63/. It indicates that the copper concentration is approximately $\sim 10$ times higher in the Te inclusion than in the surrounding CZT matrix and $~ 500$ times higher in the $\mathrm{Cd}$ inclusion. Both Figs. 13 and 14 demonstrate nicely the quantification that can be obtained by SIRIMP for the selected elements. The data reported here for the SIRIMP mode were optimized for high sensitivity and high useful yield in the spectroscopic mode 166/. The question of mass resolution in the case of SIRIMP is less relevant, since the element selected is measured in the resonant mode.

\section{CONCLUSIONS}

(1) This article describes several examples together with the various differences of secondary ion mass spectroscopy and post-ionization techniques using either a direct e-beam impact SNMS, plasma SNMS or laser ionization in the non-resonant and/or resonant mode. Much progress has been made recently due to improved mass analyzers and improved laser technology.

(2) If quantification is not the top priority, SIMS offers the highest sensitivity for spectra and dynamic range of profiles for a wide mass range.

(3) In SNMS, resonant laser post-ionization is the most quantitative method of the techniques compared here. Its drawback is the loss of analytical flexibility such as the mandatory selection of a given element. Non-resonant laser ionization has a higher efficiency than electron and plasma ionization. However, photo fragmentation during the post-ionization process may limit quantification. Key performance data of SNMS and SIMS such as mass, depth and lateral resolution as well as sensitivity and useful yield are determined also by primary ion beam and analyzer performances.

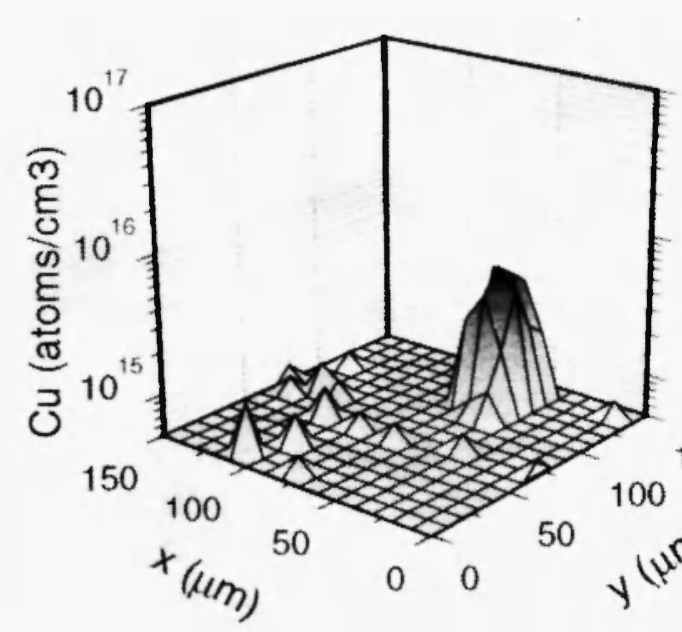

(a)

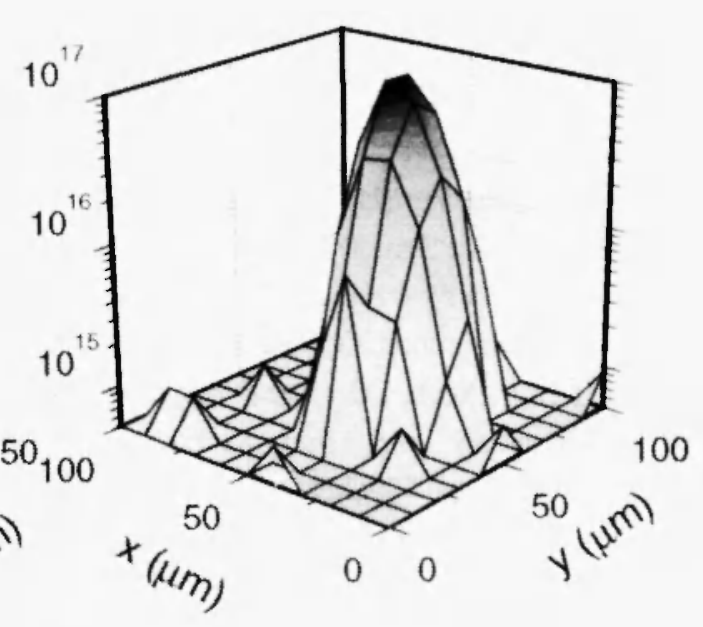

(b)

Fig. 14: SIRIMP 3D images of copper concentration around (a) tellurium and (b) cadmium inclusions in CdZnTe (CTZ) films, with permission by the authors) $/ 63 /$. 


\section{ACKNOWLEDGMENT}

The authors wish to acknowledge financial support from the Board of the Swiss Priority Program for Materials.

\section{REFERENCES:}

1. A. Benninghoven, Z. Physik 220, 159 (1969).

2. A. Benninghoven, Surface Science 28, 541 (1971).

3. A. Benninghoven, Surface Science 35, 427 (1973).

4. H.W. Werner, Surface and Interface Analysis 2, 56 (1980).

5. K. Wittmaack, Vacuum 32, 65 (1982).

6. A. Brown and J.C. Vickerman, Surface and Interface Analysis 8, 75 (1986).

7. A. Benninghoven, F.G. Rudenauer and H.W. Werner, Secondary Ion Mass Spectrometry, John Wiley \& Sons, New York, 1987.

8. S.J. Pachuta and R.G. Cooks, Chemical Review 87, 647 (1987).

9. D. Briggs and M.J. Hearn, Surface and Interface Analysis 13, 647 (1988).

10. D. Briggs, A. Brown and J.C. Vickerman, Handbook of Static Secondary Ion Mass Spectrometry, John Wiley \& Sons, Chichester, 1989.

11. J.C. Vickerman, A. Brown and N.M. Reed, eds. Secondary Ion Mass Spectrometry: Principles and Applications Oxford, Oxford Science Publications, 1989.

12. R.G. Wilson, F.A. Stevie and C.W. Magee, Secondary Ion Mass Spectrometry - A Practical Handbook for Depth Profiling and Bulk Impurity Analysis, John Wiley \& Sons, New York, 1989.

13. J.C. Rivière, Surface Analytical Techniques, Oxford Science Publications, Oxford, 1990.

14. D. Briggs and M.P. Seah, eds. Practical Surface Analysis - Secondary Ion Mass Spectroscopy, vol.2, John Wiley\&Sons, Chichester, 1992.

15. R.J. MacDonald and B.V. King, SIMS - Secondary Ion Mass Spectrometry, in Surface Analysis Methods in Materials Science, O'Connor, D.J. Sexton and R.S.C. Smart, Editors, Springer, Berlin, p. 117, 1992.

16. A. Benninghoven, B. Hagenhoff and E. Niehuis,
Anal. Chemistry 65, 630A (1993).

17. A. Benninghoven, Surface Science 300, 246 (1994).

18. H. Werner, Mikrochimica Acta 114, 107 (1994).

19. P.C. Zahn, Vacuum 45, 753 (1994).

20. P. Bertrand and L.-T. Weng, Mikrochim. Acta (suppl.) 13, 167 (1996).

21. J.C. Vickerman, D. Briggs and A. Henderson, eds. The Wiley Static SIMS Library Chichester, John Wiley \& Sons, 1996.

22. D. Briggs and M.P. Seah, eds. Practical Surface Analysis - Auger and X-ray Photoelectron Spectroscopy, vol.1, John Wiley \& Sons, Chichester, 1990.

23. E. Niehuis in SIMS $X .1993$, Yokohama, A. Benninghoven, Y. Nihei, R. Shimizu and H.W. Werner, eds., John Wiley \& Sons, 429.

24. K. Franzreb, H.J. Mathieu and D. Landolt, Surface and Interface Analysis 23, 641 (1995).

25. H. Oechsner and E. Stumpe, Appl. Phys. 14, 43 (1977).

26. H. Oechsner, Secondary Neutral Mass Spectrometry (SNMS) and its Application to Depth Profile and Interface Analysis, in Thin Film and Depth Profile Analysis, H. Oechsner, Editor, Springer, Berlin, p. 63, 1984.

27. R. Jede, O. Ganschow and U. Kaiser, Sputtered Neutral Mass Spectrometry, in Practical Surface Analysis, D. Briggs and M.P. Seah, Editors, Wiley \& Sons, Chichester, p. 425, 1992.

28. M. Terhorst, R. Mollers, E. Niehuis and A. Benninghoven, Surface and Interface Analysis 18, 824 (1992).

29. H. Oechsner in SIMS IX. 1993, Yokohama, A. Benninghoven, Y. Nihei, R. Shimizu and H.W. Werner, eds., John Wiley \& Sons, 316.

30. K. Wittmaack in SIMS IX. 1993, Yokohama, A. Benninghoven, Y. Nihei, R. Shimizu and H.W. Werner, eds., John Wiley \& Sons, 309.

31. H.F. Arlinghaus, T.J. Whitaker, C.F. Joyner, P. Kwoka, B. Jacobson and J. Tower in SIMS $X$. 1995, Münster, A. Benninghoven, B. Hagenhoff and H.W. Werner, eds., John Wiley \& Sons, 123.

32. D. Briggs, Characterization of Solid Polymers: New Techniques and Developments, Chapman \& Hall, London, p. 312, 1994. 
33. J.P. Biersack, Ion Beam Modification of Insulators, Elsevier Science Publishers, 648, Amsterdam, 1987.

34. J.B. Lhoest, J.L. Dewez and P. Bertrand, Nucl. Instr. Meth. Phys. Res. B 105, 322 (1995).

35. P. Sigmund, ed. Sputtering by Particle Bombardment. Physical Sputtering of Single-Element. Solids Berlin, p. 9, Springer, 1981.

36. N.M. Reed and J.C. Vickerman, Surface Characterization of Advanced Polymers, VCH Verlagsgesellschaft, Weinheim, p. 83, 1993.

37. G.J. Leggett and J.C. Vickerman, Int. Journal of Mass Spectrometry and Ion Processes 122, 281 (1992).

38. K. Wittmaack, Phil. Trans. R. Soc. Lond A 354, 2731 (1996).

39. H. Liebl, $A d v$. in Mass Spectr. 7A, 751 (1978).

40. E. Niehuis, T. Heller, $H$. Feld and $A$. Benninghoven in SIMS $V .1985$, A. Benninghoven, R.J. Colton, D.S. Simons and H.W. Werner, eds., Springer N.Y., 188.

41. B.W. Schueler, Microsc. Microanal. Microstruct. 3, 119 (1992).

42. A. Benninghoven, K.T.F. Janssen, J. Tümpner and H.W. Wemer, eds. Secondary Ion Mass. Spectrometry SIMS VIII Amsterdam 1991, John Wiley \& Sons, 1992.

43. A. Benninghoven, Y. Nihei, R. Shimizu and H.W. Werner, eds. Secondary Ion Mass Spectrometry SIMS $L X$ Yokohama 1993, John Wiley \& Sons, 1994.

44. H.J. Mathieu, B. Reihl and D. Briggs, eds. ECASLA '95 Proceedings Montreux 1995, John Wiley \& Sons, 1996.

45. A. Benninghoven, B. Hagenhoff and H.W. Werner, eds. Secondary Ion Mass Spectrometry SIMS X Münster 1995, John Wiley \& Sons, 1997.

46. H.A. Storms, K.F. Brown and J.D. Stein, Anal. Chem. 49, 2023 (1997).

47. R.E. Honig, The Application of Mass Spectroscopy to the Study of Surfaces and Sputtering, in Advances in Mass Spectroscopy, J.D. Waldron, Editor, Pergamon Press, London, p. $162,1959$.

48. J.R. Woodyard and C.B. Cooper, J. Appl. Phys. 35, 1107 (1964).
49. H. Gnaser, J. Fleischhauer and W.O. Hofer, Appl. Phys. A 37, 211 (1985).

50. D. Lipinsky, R. Jede, J. Tümpner, O. Ganshow and A. Benninghoven, J. Vac. Sci. Technol. A 3, 2035 (1985).

51. H.U. Gersch and K. Wittmaack, J. Vac. Sci. Technol. A 11, 125 (1993).

52. S. Kato, M. Hamagaki, T. Hara, K Aoyagi, S. Namba, S. Hayashi and H. Yashiro, Nucl. Instr. Meth. Phys. Res. B35, 550 (1988).

53. W. Bieck, H. Gnaser and H. Oechsner, Appl. Phys. Lett. 63, 845 (1993).

54. W. Bieck, H. Gnaser and H. Oechnser, J. Vac. Sci. Techn. A 12, 2537 (1994).

55. C.H. Becker and K.T. Gillen, Anal. Chem. 56, 1671 (1984).

56. C.H. Becker, J. Vac. Sci. Technol. A 5, 1181 (1987).

57. J.B. Pallix, C.H. Becker and N. Newman, J. Vac. Sci. Techn. A 6, 1049 (1988).

58. D.L. Pappas, D.M. Hrubowchack, M.H. Ervin and N. Winograd, Science 243, 64 (1989).

59. N. Thonnard, J.E. Parks, R.D. Willis, L.J. Moore and H.F. Arlinghaus, Surface and. Interface Analysis 14, 751 (1989).

60. S.W. Downey, A.B. Emerson and R.F. Kopf, Inst. Phys. Conf. Ser. 114, 401 (1990).

61. MJ. Pellin, C.E. Young, W.F. Calaway, J.E. Whitten, D.M. Gruen, J.B. Blum, I.D. Hutcheon and G.J.Wasserburg, Phil. Trans. Royal Soc. Lond. A333, 133 (1990).

62. H.F. Arlinghaus, M.T. Spaar and N. Thonnard, J. Vac. Sci. Techn. A 11, 2317 (1993).

63. H.F. Arlinghaus, C.F. Joyner, J. Tower and S. Sen in SIMS X. 1995, Münster, A. Benninghoven, B. Hagenhoff, H.W. Werner, eds., John Wiley \& Sons, 463.

64. H.F. Arlinghaus, T.J. Whitaker and C.F. Joyner in SIMS X. 1995, Münster, A. Benninghoven, B. Hagenhoff, H.W. Werner, eds., John Wiley \& Sons, 839.

65. P.D. Bisschop, J. Gomez and W. Vandervorst in SIMS X. 1995, Münster, A. Benninghoven, B. Hagenhoff and H.W. Werner, eds., John Wiley \& Sons, 793.

66. H.F. Arlinghaus and C.F. Joyner, J. Vac. Sci. 
Technol. B 14, 1 (1996).

67. C.H. Becker, Ion Spectroscopy for Surface Analysis, in Methods of Surface Characterization, A.W. Czanderna, Editor, Plenum Press, New York, ch. 4, 1990.

68. Y.L. Wang, R. Levi-Setti and J. Chabala, Scanning Microscopy 1, 1 (1987).

69. A. Wucher, K. Franzreb, H.J. Mathieu and D. Landolt, Surface and Interface Analysis 23, 844 (1995).

70. M. Terhorst, G. Kampwerth, E. Niehuis and A. Benninghoven in SIMS VIII. 1991, Amsterdam, A. Benninghoven, K.T.F. Janssen, J. Tümpner and H.W. Werner, eds., John Wiley \& Sons, 567.

71. M. Terhorst, R Mollers, A. Schnieders, E. Niehuis and A. Benninghoven in SIMS IX. 1993, Yokohama, A. Benninghoven, Y. Nihei, R. Shimizu and H.W. Werner, eds., John Wiley \& Sons, 434.

72. S. Hayashi and Y. Hashiguchi in SLMS VIII. 1991, Amsterdam, A. Benninghoven, K.T.F. Janssen, J. Tümpner and H.W. Werner, eds., John Wiley \& Sons, 575.

73. G. Kampwerth, M. Terhorst, E. Niehuis and A. Benninghoven in SLMS VII. 1991, Amsterdam, A. Benninghoven, K.T.F. Janssen, J. Tümpner and H.W. Werner, eds., John Wiley \& Sons, 563.

74. A. Schnieders, R. Möllers, M Terhorst, H.G. Cramer, E. Niehuis and A. Benninghoven, J. Vac. Sci. Technol. B 14, 2712 (1996).
75. D. Landolt, P. Schmutz and H.J. Mathieu, Mat. Science Forum 185-188, 313 (1994).

76. W. Berthold and A. Wucher, Surface and Interface Analysis 23, 393 (1995).

77. S.P. Mouncey, L. Moro and C. Becker, Appl. Surf. Sci. 52, 39 (1991).

78. M. Terhorst, $R$ Möllers, E. Niehuis and A. Benninghoven, Org. Mass Spectrometry 27, 1993 (1992).

79. C.R. Ayre, L. Moro and C.H. Becker, Anal. Chem. 66, 1610 (1994).

80. C.L. Brummel, K.F. Willey, J.C. Vickerman and N. Winograd, Int. J. Mass Spectrometry 143, 257 (1995).

81. G.K. Nicolussi, M.J. Pellin, K.R. Lykke, J.L. Trevor, D.E. Mencer and A.M Davis, Surface and Interface Analysis 24, 363 (1996).

82. K.F. Willey, C.L. Brummel and N. Winograd in SIMS X. 1995, Münster, A. Benninghoven, B. Hagenhoff and H.W. Werner, eds., John Wiley \& Sons, 797.

83. A. Wucher and $\mathrm{H}$. Oechsner, Nucl. Instrum. Phys. Res. B18, 458 (1987).

84. H. Schoof, $\mathrm{PhD}$. Thesis, 1981, Technical University Clausthal / Germany.

* $\mathrm{Ta}_{2} \mathrm{O}_{5} / \mathrm{Ta}$ standard no 261 - Joint Research Center IRRM, Retieseweg, B-2440 Geel, Belgium Management of Reference Materials 